\title{
CONCEPÇÃO DE COORDENADORES DA ATENÇÃO BÁSICA SOBRE EDUCAÇÃO PERMANENTE EM SAÚDE: APROXIMAÇÕES E DISTANCIAMENTOS COM PRESSUPOSTOS FREIREANOS
}

Coordinators primary care design on permanent health education: similarities and differences with assumptions freirean

Carine Vendruscolo ${ }^{1}$, Camila Alessandra Anastácio², Denise Antunes de Azambuja Zocche $^{3}$, Leticia de Lima Trindade ${ }^{4}$, Daiana Kloh ${ }^{5}$

1 Enfermeira, Doutora em Enfermagem pelo Programa de Pós-Graduação em Enfermagem da Universidade Federal de Santa Catarina (UFSC), docente do Departamento de Enfermagem da Universidade do Estado de Santa Catarina (UDESC), membro do Grupo de Pesquisa Educação em Enfermagem e Saúde (EDEN/PEN/UFSC) e do Grupo de Estudos sobre Educação e Trabalho (GESTRA/UDESC).

2 Enfermeira graduada pela UDESC.

${ }^{3}$ Enfermeira, Doutora em Enfermagem pela Universidade Federal do Rio Grande do Sul (UFRGS), docente do Departamento de Enfermagem da UDESC.

${ }^{4}$ Enfermeira, Doutora em Enfermagem pela UFSC, docente do Departamento de Enfermagem da UDESC.

${ }^{5}$ Enfermeira, Doutoranda em Enfermagem pela UFSC, docente do Departamento de Enfermagem da UDESC.

\section{Endereço para correspondência:}

Carine Vendruscolo

Rua Martinho Lutero, 975 E, Bairro São Cristóvão, Chapecó, Santa Catarina. Telefone: (49) 99203222.

Email: carine.vendruscolo@udesc.br 


\title{
Resumo
}

Buscou-se identificar as concepções teórico-filosóficas que permeiam o ideário dos coordenadores da Atenção Básica ( $A B$ ) sobre processos de Educação Permanente em Saúde (EPS), desenvolvidos em um município do Oeste de Santa Catarina, estabelecendo a sua aproximação com o referencial proposto por Paulo Freire. Tratase de uma pesquisa qualitativa, descritiva e exploratória. As informações foram obtidas mediante entrevistas com coordenadores da AB, em 2013. A análise ancorouse na análise de conteúdo de Bardin. As concepções sugerem forte predominância da abordagem bancária nos processos de EPS, baseada em capacitações e palestras. A EPS, por vezes, é confundida com Educação Continuada, focada em conhecimentos técnico-científicos de cada área. Parte dos sujeitos percebe as ações como inerentes ao processo de trabalho da equipe, tangenciando a proposta freireana, base da Política de EPS. Para que esta se consolide como operadora de mudanças nas práticas da $\mathrm{AB}$, será preciso maior compreensão e envolvimento dos coordenadores.

Palavras-chave: Educação Continuada; Atenção Básica à Saúde; Processo de Trabalho; Sistema Único de Saúde.

\begin{abstract}
It was sought to identify the theoretical and philosophical concepts that underlie the ideology of the coordinators of the Primary Care on the processes of Permanent Education in Health developed in a territory, establishing its approach as the proposed reference by Paulo Freire. It is a qualitative, descriptive and exploratory. The data were obtained through semi-structured interviews with coordinators of the Primary Care in a city in western Santa Catarina, in 2013. Analysis is anchored in the Bardin Content Analysis. The conceptions suggest strong predominance of banking approach in Permanent Education processes, based on training and lectures. The Permanent Education it is sometimes mistaken for continued education, focused on technical and scientific knowledge of each area. Most of the individuals perceive the actions as inherent to the work process of the healthcare team, approaching with Freire's proposal, base of the Permanent Education Policy. In order to this may be consolidated
\end{abstract}


Artigo Original

\section{Gestão em Saúde}

as operator of changes in the practice of Primary Care, it will be need greater understanding and involvement of the coordinators.

Keywords: Education, Continuing; Primary Health Care; Work Process; Unified Health System.

\section{INTRODUÇÃO}

Na década de 1980, a Educação Permanente em Saúde (EPS) é admitida como uma prioridade junto à Organização Panamericana de Saúde e à Organização Mundial da Saúde (OPAS/OMS) ${ }^{1}$. No Brasil, tais discussões são contemporâneas ao movimento que culminou com a VIII Conferência Nacional de Saúde, em 1986, para mudança do modelo de saúde, e que deu origem à proposta do Sistema Único de Saúde (SUS). Ao longo do desenvolvimento e consolidação desse Sistema, as questões do trabalho em saúde ganharam destaque, seja como elemento da agenda de lutas ou como desafio para a sua implantação e implementação².

No âmbito das medidas de consolidação do Sistema, no início dos anos 2000, houve grande expansão no número de equipes da Estratégia Saúde da Família (ESF). Considerada elemento central da Política Nacional de Atenção Básica à Saúde (ABS), a Estratégia visa o fortalecimento e organização desse nível de atenção à saúde no Brasil e tem como foco a atuação junto às famílias em seu território, favorecendo a ampliação do acesso e a reorientação das práticas na direção da interdisciplinaridade, da integralidade e da Promoção da Saúde. A ESF propõe a mudança na concepção do processo saúde-doença, distanciando-se do modelo tradicional de oferta de serviços voltados para a doença e investindo em ações que articulam a saúde com condições e qualidade de vida ${ }^{3}$.

Criada em 1994, a ESF, inicialmente conhecida como Programa Saúde da Família (PSF), emerge no Brasil como uma estratégia de reorientação do modelo assistencial e qualificação das técnicas dos trabalhadores da $A B S$, em conformidade com os princípios do SUS. A busca de novos modelos de atenção decorre de um momento histórico social, no qual o modelo tecnicista, hospitalocêntrico e médico centrado não atende mais à emergência das mudanças do mundo do trabalho em saúde brasileiro e, consequentemente, às necessidades de saúde das pessoas ${ }^{4-5}$. 


\section{Artigo Original}

\section{Gestão em Saúde}

Sendo assim, a ESF é considerada uma das mais relevantes propostas do Ministério da Saúde (MS) para reorientar o modelo assistencial do SUS por meio da ABS ${ }^{6}$. Para tanto, é fundamental a qualificação das práticas daqueles que atuam diretamente com o usuário do Sistema, por meio do permanente processo de construção de conhecimentos, perfazendo uma busca de qualidade de vida pessoal e intelectual do trabalhador, com base no marco constitucional que designa ao SUS a ordenação da formação de recursos humanos na área da saúde ${ }^{7}$.

Com os problemas oriundos da expansão da ESF no Brasil, constatou-se que era preciso rever a formação dos profissionais, pois enquanto não se rompesse a ótica positivista e unicausal do ensino na área da saúde, não se avançaria na direção que o SUS propõe, ou seja, de um modelo centrado no trabalho em equipes multidisciplinares e na alta resolubilidade da ABS. Além dos Pólos de Capacitação, com o propósito de direcionar a formação das equipes da ESF, foram criadas, de 1995 a 2000, mais de 20 residências multiprofissionais em Saúde da Família e mais de 50 especializações na mesma área. Embora tenha se iniciado a reestruturação dos cursos de medicina, o Ministério da Educação (MEC) não tinha nenhum envolvimento nesse processo, até então ${ }^{8}$.

Em 2003, o Ministério da Saúde (MS), visando promover uma aproximação com o MEC, criou e instituiu o Departamento de Gestão da Educação na Saúde (DEGES), no âmbito da Secretaria de Gestão do Trabalho e da Educação na Saúde (SGTES), com vistas a enfrentar as questões que envolvem a formação e o desenvolvimento dos profissionais de saúde.

Nessa direção, para além da EPS, percebe-se a necessidade de uma pedagogia fundamentada em processos de coparticipação e envolvimento do serviço, dos centros formadores e dos usuários, pois os profissionais estão diretamente ligados ao cotidiano da comunidade, principalmente em se tratando da Saúde Coletiva $^{9}$. Assim, os movimentos iniciados na década de 1980 culminaram com a instituição da Política Nacional de Educação Permanente em Saúde (PNEPS), em 2004, a qual foi revisada por meio da Portaria $n^{\circ}$ 1.996, de agosto de 2007.

Com tais argumentos, o conceito de EPS se ancora na aprendizagem significativa, ou seja, na troca de saberes entre os sujeitos envolvidos e na aplicabilidade do processo educativo no dia-a-dia do trabalho em saúde. $O$ aprender e o ensinar estão indissociáveis e implicam na inevitável mudança da realidade. A 


\section{Artigo Original}

\section{Gestão em Saúde}

integração entre teoria e prática se fundamenta na ação-reflexão-ação, a partir do cotidiano, e não somente na análise das práticas oriundas desse processo ${ }^{10-13}$.

A PNEPS sinaliza que a educação permanente pode ser compreendida como aprendizagem-trabalho, pois se desenvolve no cotidiano das pessoas e das organizações. Ela se realiza mediante os nós críticos do processo de trabalho em saúde e, a fim de resolver tais problemas, leva em consideração os conhecimentos e as experiências das pessoas. Propõe, assim, que os processos de educação dos trabalhadores ocorram pela problematização do processo de trabalho, e pondera que as demandas de formação e desenvolvimento dos mesmos sejam pautadas pelas necessidades de saúde dos indivíduos e coletividades. Os processos de EPS têm como objetivos, portanto, a transformação das práticas profissionais e da própria organização do trabalho ${ }^{14}$.

Para o educador brasileiro Paulo Freire ${ }^{10}$, o indivíduo, como um ser inacabado, no momento em que tem consciência de sua inconclusão, encontra as raízes da educação como manifestação exclusivamente humana. Desse modo, a educação é um "que fazer" permanente dos seres humanos e do contínuo refazer da realidade. Nesta perspectiva, a EPS segue tais pressupostos pedagógicos e considera a aprendizagem significativa, cujo objetivo principal é a transformação real das práticas. O público-alvo dos processos educativos são as equipes de atenção e de gestão interdisciplinar, em qualquer esfera do Sistema de Saúde, incluindo os usuários (controle social). As atividades educativas são construídas a partir da análise coletiva dos processos de trabalho, levando em conta as necessidades específicas de profissionais e equipes, considerando também os pressupostos da Política Nacional de Humanização, como dispositivo importante para efetivação de muitas ações ${ }^{15}$.

De maneira convergente com as diretrizes da PNEPS, as demandas para ações educativas ocorrem mediante a problematização - concepção pedagógica transformadora e emancipatória de Freire ${ }^{11,12}$ - do processo de trabalho. Requer, portanto, ações no âmbito da organização do trabalho, da interação com redes de gestão e de serviços de saúde e do controle social no setor. A qualificação dos trabalhadores passa, também, a ser valorizada e observada a partir do "saber-ser", e não somente do "saber-fazer". A habilidade de resolver problemas e enfrentar situações de imprevisibilidade e as mobilizações da inteligência para fazer face aos 


\section{Artigo Original}

\section{Gestão em Saúde}

desafios do trabalho são características desta nova proposta de qualificação, sendo compreendida como uma estratégia de gestão ${ }^{16}$.

Por entender que a atual PNEPS é guiada por tais pressupostos, e por acreditar na Educação Permanente como dispositivo para a qualificação das práticas na $A B$, este estudo orienta-se a partir do seguinte objetivo: conhecer a percepção dos coordenadores de unidades básicas de saúde sobre os processos de EPS desenvolvidos no âmbito da $A B$, na rede municipal de saúde de Chapecó, oeste de Santa Catarina.

\section{METODOLOGIA}

Trata-se de um estudo descritivo e exploratório, com abordagem qualitativa. Foi realizado nas unidades básicas de saúde (Centros de Saúde - CS) do município de Chapecó, oeste de Santa Catarina.

Com o processo de regionalização, proposto pelo MS, a Região de Saúde consiste em uma base territorial de planejamento da atenção à saúde, a ser definida pela Secretaria Estadual de Saúde, de acordo com especificidades locais ${ }^{17}$. A Região de Saúde Oeste de SC é formada por 26 municípios e regida por uma Comissão Intergestores Regional (CIR), assessorada, no que tange à EPS, por uma Comissão de Integração Ensino Serviço (CIES). As demandas de ações de educação permanente apresentadas pelos municípios que compõe a referida Região devem ser organizadas, conforme previsto no Anexo II da Portaria GM/MS n 1.996/07, a partir da elaboração de um Plano de Ações Regionais para Educação Permanente em Saúde (PAREPS) ${ }^{15}$.

Chapecó é município pólo da Região Oeste de SC - uma das 16 do Estado de SC -, sediando a CIR e a CIES dessa região. No âmbito da rede básica de atenção à saúde do município, existem, atualmente, 26 Centros de Saúde (CS).

A pesquisa foi realizada com 12 coordenadores dos CS, utilizando-se como critério para inclusão dos sujeitos: atuar no CS no mínimo seis meses, pois nesse período é possível inserir-se na rotina do serviço e, consequentemente, obter maior representatividade.

Como técnica para produção e registro das informações, foram realizadas entrevistas semiestruturadas, as quais foram gravadas e transcritas, após livre 


\section{Artigo Original \\ Gestão em Saúde}

consentimento dos participantes. Para tratamento das informações, foi utilizada a Análise de Conteúdo de Bardin (2011) ${ }^{18}$, tendo como marco teórico-filosófico as obras do educador e cientista social Paulo Freire. Assim, o material de análise passou por diferentes fases: pré-análise; exploração do material; tratamento dos resultados, inferência e interpretação. Essa forma de análise originou categorias (C) e subcategorias (S), as quais foram organizadas na tabela 1, facilitando a visualização geral do processo de análise obtido nos diálogos.

Tabela 1. Categorias e Subcategorias que emergiram a partir da análise dos resultados.

\begin{tabular}{cc}
\hline CATEGORIAS (C) & SUBCATEGORIAS (S) \\
\hline C1: Educação permanente em saúde como & S1: Atualização constante \\
qualificação profissional na atenção básica & S2: Processo norteador do trabalho \\
& S3: Trabalho multiprofissional \\
C2: Educação permanente em saúde na & S4: Capacitações esporádicas \\
atenção básica: aprender fazendo & S2: Falta de interesse profissional \\
& S3: Educação para a comunidade
\end{tabular}

\section{Fonte: Próprio Autor}

Por tratar-se de uma investigação científica que conta com indivíduos como sujeitos, foram observadas as exigências éticas e científicas sobre a pesquisa envolvendo seres humanos, conforme a Resolução 466/2012 do Conselho Nacional de Saúde, obtendo parecer favorável sob o protocolo n³97.390/2013.

Os participantes deste estudo serão representados por codinomes inspirados em romances brasileiros, de modo a preservar a identidade dos mesmos. 
O perfil dos participantes deste estudo está apresentado na tabela 2. Dentre os coordenadores dos CS, há uma predominância do gênero feminino (10); as faixas etárias encontram-se entre 25 e 58 anos e o cargo é ocupado, na maioria das vezes (10), por enfermeiros, sendo dois dos CS com coordenadores dentistas. Apenas um dos coordenadores não possui pós-graduação, sendo que a maior parte das especializações realizadas foram nas áreas de saúde da família e gestão em saúde.

Tabela 2. Perfil dos participantes do estudo.

\begin{tabular}{|c|c|c|}
\hline CODINOME & FORMAÇÃO & $\begin{array}{c}\text { TEMPO DE } \\
\text { ATUAÇÃO NA AB }\end{array}$ \\
\hline A moreninha & $\begin{array}{c}\text { Superior em Enfermagem, } \\
\text { especialista em Saúde da família }\end{array}$ & 4 anos \\
\hline A Condessa Vésper & $\begin{array}{l}\text { Superior em Enfermagem, } \\
\text { especialista em obstetrícia }\end{array}$ & 3 anos \\
\hline Macunaíma & $\begin{array}{c}\text { Superior em Enfermagem, } \\
\text { especialista em gestão e gerência, } \\
\text { saúde da família e saúde do } \\
\text { trabalhador }\end{array}$ & 1 ano e 5 meses \\
\hline Inocência & $\begin{array}{c}\text { Superior em Enfermagem, } \\
\text { especialista em gestão e } \\
\text { gerenciamento das unidades do SUS }\end{array}$ & 6 meses \\
\hline Dom Quixote & $\begin{array}{l}\text { Superior em Enfermagem, } \\
\text { especialista em saúde da família e } \\
\text { administração dos serviços de saúde }\end{array}$ & 6 meses \\
\hline Senhora & $\begin{array}{l}\text { Superior em Enfermagem, } \\
\text { especialista em saúde da família }\end{array}$ & 3 anos \\
\hline O primo Basílio & $\begin{array}{l}\text { Superior em Enfermagem, } \\
\text { especialista em vigilância sanitária e } \\
\text { epidemiologia }\end{array}$ & 6 meses \\
\hline A escrava Isaura & Superior em Odontologia & 8 meses \\
\hline Iracema & $\begin{array}{c}\text { Superior em Enfermagem, } \\
\text { especialista em saúde da família }\end{array}$ & 6 meses \\
\hline
\end{tabular}




\begin{tabular}{ccc}
\hline \hline CODINOME & FORMAÇÃo & $\begin{array}{c}\text { TEMPO DE } \\
\text { ATUAÇÃo NA AB }\end{array}$ \\
\hline A Viuvinha & $\begin{array}{c}\text { Superior em Enfermagem, } \\
\text { especialista em gestão em saúde e } \\
\text { outras cinco especializações } \\
\text { Superior em Enfermagem, }\end{array}$ & 2 anos \\
Bemórias Póstumas de & $\begin{array}{c}\text { especialista em enfermagem do } \\
\text { trabalho }\end{array}$ & 6 meses \\
Dom Casmurro & Superior Odontologia, especialista em & \\
& saúde da família & 4 anos
\end{tabular}

Fonte: Próprio Autor

São atribuições comuns a todos os profissionais das equipes de $A B S$, de acordo com a Política Nacional ${ }^{3}$, certos processos que abarcam a gestão em saúde, como a territorialização e o mapeamento da área da atuação, a atualização dos cadastros das famílias que residem naquele território, o planejamento das ações de cuidado, os registros sobre suas condições, a educação em saúde, entre outras. Isso pressupõe que, em tese, qualquer profissional da equipe pode exercer o cargo de coordenador/gestor, desde que possua habilidades para desenvolver tais ações. $O$ que se percebe na prática, contudo, é que a maioria dos cargos de coordenação das equipes é ocupado por enfermeiros.

Com a criação do SUS, os profissionais da saúde, sobretudo o profissional enfermeiro, ampliou a sua inserção e atuação no campo comunitário e social. Isso se deve também às oportunidades oferecidas pela ESF, a qual proporcionou maior visibilidade e se apresenta como lócus flexível para a emancipação e a transformação social. Para atuação nesse contexto, a prática do enfermeiro vai além da dimensão técnico-assistencial ou da aplicação dos conhecimentos técnico-científicos, concentrando-se em saberes que demandam as inter-relações e a dinâmica coletivosocial de todos os sujeitos da equipe de saúde e usuários do Sistema 5 . Considera-se que, para ser parte da equipe de Saúde da Família, é imprescindível o conhecimento cientifico e tecnológico, porém também se faz necessário o conhecimento social referente ao processo de cuidar, o adequado preparo como gestor, o que inclui planejar e avaliar políticas, além de coordenar e conduzir sistemas e serviços de saúde ${ }^{19}$. Soma-se a isso o fato de que, em qualquer área da saúde, um certificado de 
Artigo Original

Gestão em Saúde

graduação nem sempre é sinônimo de qualificação necessária, pois o mundo está em constante transformação, pressupondo o dever de atualização dos profissionais, com base nas necessidades que advém dessas mudanças.

O educador Paulo Freire acreditava que os seres humanos se tornam sujeitos sociais, críticos e reflexivos por meio da práxis, união homogênea entre a ação e reflexão sobre o mundo, a fim de transformá-lo. Por meio da práxis os sujeitos são capazes de agir de forma consciente sobre a realidade, pois a ação-reflexão contribui para tal revelação, mediada pelo diálogo e pelas relações construídas no interior das estruturas histórico-sociais ${ }^{10}$. No contexto do trabalho no SUS, é possível refletir sobre possibilidades reais de mudança na realidade dos serviços, tendo a EPS como dispositivo, por meio da troca de informações entre a equipe sobre os nós críticos que advém desse cotidiano, no sentido de qualificar a prática ${ }^{10,11}$.

\section{EDUCAÇÃO PERMANENTE EM SAÚDE COMO QUALIFICAÇÃO PROFISSIONAL NA ATENÇÃO BÁSICA}

De acordo com os discursos dos coordenadores dos CS, as ações de EPS objetivam qualificar o processo de trabalho na rede básica de saúde, e vêm sendo realizadas mediante atualizações constantes (S1), desenvolvidas mensalmente, sobre temáticas/conteúdos que emergem das demandas da equipe de saúde ou das propostas do MS, como, por exemplo, os protocolos assistenciais, agravos mais frequentes no território ou, ainda, o processo de trabalho na ESF e as redes de cuidado.

Eu fiz diversos cursos de atualização, mês passado teve um de hepatites, quase todo mês tem cursos para fazer (Iracema).

[...] todo o mês a gente tem essas capacitações para relembrar e se atualizar nos conteúdos (O Primo Basílio).

[...] a própria saúde da família e a saúde da criança, idoso, estas são necessidades. Saúde do trabalhador e saúde mental são também grandes necessidades [de atualização] (Inocência). 
Essa perspectiva dos sujeitos, em parte, distancia-se dos pressupostos da EPS, pois os sujeitos apontam os processos de formação como uma garantia de atualização das técnicas/conteúdos do trabalho em saúde, de forma fragmentada, voltando-se à proposta de Educação Continuada. A EPS propõe a reestruturação dos serviços, a partir do cotidiano de trabalho, tendo o profissional como sujeito, no centro do processo de ensino aprendizagem ${ }^{20}$.

Os termos Educação Permanente e Educação Continuada percorreram uma trajetória histórica em relação ao seu conceito. De acordo com a literatura, o modelo convencional, orientador da Educação Continuada, compreende o trabalho como aplicação do conhecimento teórico especializado, enquanto na Educação Permanente compreende que as demandas educativas ocorrem no processo de trabalho, como resultado da cultura e do cotidiano laboral. A EPS tem como objetivo promover mudança institucional, fortalecer as ações de equipe e transformar práticas técnicas e sociais. Isso implica em uma pedagogia centrada na resolução de problemas e efetuada no ambiente de trabalho, de maneira a promover a apropriação do saber científico, configurando-se como responsabilidade da instituição na qual o profissional atua $^{21}$. De maneira convergente, os pressupostos teóricos que orientam a EPS pressupõem que, quando o indivíduo conhece a sua realidade, toma consciência das suas dificuldades e encontra recursos para transformá-la ${ }^{11}$.

Outra perspectiva encontrada, quanto à finalidade para desenvolvimentos das ações de EPS, foi como processo norteador do trabalho (S2), ao possibilitar que o profissional compreenda e se identifique com as atividades do trabalho na ESF. A realização dessas ações configura-se como instrumento necessário para introduzir o profissional no processo de trabalho e guiá-lo, desde o início da sua atividade laboral, permitindo essa apropriação.

[...] [o curso introdutório] fala tudo, sobre conferência de saúde, projetos de leis do SUS, atuação dos profissionais, portarias, tudo para nortear o trabalho mesmo (A Condessa Vésper).

[...] [os profissionais] entraram de paraquedas sem saber praticamente nada, 0 que é saúde da família (Escrava Isaura). 
[...] quando a gente entra acho que deveria fazer o introdutório (Dom Quixote).

[...] o curso introdutório é bem importante, sobre saúde da família (Senhora).

O Curso Introdutório para Equipes de Saúde da Família mencionado pelo participante, obrigatório, de acordo com o $\mathrm{MS}^{22}$, foi oferecido aos trabalhadores do município pela Gerência Estadual de Saúde em parceria com a Escola de Saúde Pública do Estado de SC, em duas edições, entre os anos de 2008 e 2011.

Nessa subcategoria chama a atenção o fato de a rede municipal não oferecer regularmente a base introdutória ao profissional admitido, sobretudo quanto às bases legais que norteiam o SUS, o que poderia facilitar o processo de trabalho. Fica clara a noção da importância da práxis, ao colocar-se em favor de um estímulo permanente de refletir sobre condições reais do cotidiano, por meio de uma teoria que precede a ação, considerando-se que a reflexão norteia a mudança da ação ${ }^{12}$. Assim, nortear o trabalho em saúde, por meio de exercícios de reflexão e ação, constitui-se elemento essencial para a qualificação do cuidado, visto que, se desde a admissão do profissional este for familiarizado à essência do processo, ele será conduzido pelo cotidiano a colocar em análise seu processo de trabalho, o que favorecerá a construção de conhecimentos advindos da prática.

$\mathrm{Na}$ concepção dos sujeitos entrevistados, as ações de EPS estão, diretamente, ligadas a todos os sujeitos entrelaçados pelo processo de trabalho, desde o coordenador do CS até os profissionais responsáveis pelos serviços gerais. Esta subcategoria incidiu sobre a qualificação voltada ao trabalho multiprofissional (S3). O reconhecimento do trabalho inter ou multiprofissional, como elemento importante do trabalho nas equipes de saúde, parte da própria coordenação do CS, o qual percebe a necessidade de realizar ações no cotidiano do processo de trabalho, para maior resolubilidade da atenção à saúde da comunidade.

Também são citadas estratégias do MS, implementadas pela rede de $A B$, como fomentadoras da EPS, como é o caso do Núcleo de Apoio à Saúde da Família (NASF). Essas possibilidades foram percebidas como um impasse, em alguns momentos, por haver restrição à participação dos sujeitos nas atividades. Segundo os coordenadores, as ações por vezes são destinadas a determinado grupo profissional, 
Artigo Original

Gestão em Saúde

favorecendo algumas categorias em detrimento de outras, como apresentado nos discursos a seguir:

Na verdade, educação permanente tem que ser em todas as áreas, seguido tem que renovar [...] (Senhora).

Eles [profissionais do NASF] vêm para um apoio matricial e como educação permanente também. Então, tem esse apoio que a gente recebe, tendo várias atividades, de vários profissionais e várias áreas também (Macunaíma).

Os médicos têm uma capacitação de rotina, pelo que eu percebi, porque eles têm encontros mensais de capacitações para os médicos, para enfermagem tem um pouco menos (Memórias póstumas de Brás Cubas).

O NASF foi criado por meio da Portaria GM n.154, de janeiro de 2008, reeditada em março de 2008, com o objetivo de integrar a assistência à saúde nas equipes de ESF e oferecer subsídios às equipes para consolidação da rede de serviços e resolubilidade da ABS. A estratégia prevê o conceito de atuação interdisciplinar e matriciamento das equipes, para contribuir na resolução dos problemas, por meio do diálogo permanente com estas ${ }^{23}$.

Nessa direção, cumpre contextualizar o diálogo como necessidade existencial, condição básica para o conhecimento. $O$ ato de conhecer ocorre a partir de um processo social, mediado pelo diálogo, ou seja, é por meio dele que se obtém a compreensão do significado social dos temas, em que estão em discussão, e que se toma consciência da realidade ${ }^{24}$. O diálogo ocorre na comunicação entre os sujeitos, a partir de um encontro, que se realiza na práxis, na ação com reflexão, como já mencionado, fundamentando-se no compromisso com a transformação social ${ }^{11}$.

Um ideário bastante frequente encontrado nos discursos tem relação com ações de EPS, como capacitações esporádicas (S4) buscadas pelos próprios profissionais. Os coordenadores ainda sugerem o apoio incipiente da Secretaria Municipal de Saúde quanto à liberação dos profissionais para tais capacitações, por vezes no formato de cursos de pós-graduação: 


\section{Artigo Original}

\section{Gestão em Saúde}

[...] a minha pós de administração em 2009, a Secretaria pagou metade, todas nós que estávamos na coordenação, [...] e depois só capacitações esporádicas (Dom Quixote).

[...] via Secretaria Municipal muito pouco [...] a gente não tem isso, dentro do que a gente precisaria aqui! A maioria dos profissionais sai em busca por recurso próprio, para melhorar conhecimento na área em que a gente trabalha (A Viuvinha).

Percebe-se que apesar das dificuldades encontradas para a realização das capacitações, o que prevalece é o interesse de alguns profissionais em buscar e aprimorar conhecimentos para melhoria de suas práticas. Nessa vertente, a educação brota como um elemento essencial para impulsionar a melhoria dos serviços, bem como para que o perfil do trabalhador esteja em consonância com os princípios e diretrizes do SUS. Embora sejam perceptíveis movimentos nesse sentido, tendo as práticas e o diálogo como disparadores, o que toma vulto é um ideário voltado às características da Educação Continuada, tendo como foco a aplicação do conhecimento teórico especializado.

\section{EDUCAÇÃo PERMANENTE EM SAÚdE NA ATENÇÃO BÁSICA: APRENDER FAZENDO}

A concepção dos coordenadores dos CS sobre EPS também demonstra que ela pode estar vinculada à qualificação focada nas necessidades cotidianas (S1), ou seja, as ações de EPS emergem das problemáticas e dificuldades evidenciadas no cotidiano do processo laboral.

[...] e sempre tem a cada 60 dias ou até antes, conforme a necessidade vão sendo chamados [à participar de algum processo educativo, pela Secretaria de Saúde], sempre tem educação permanente [...] (A Moreninha). 


\section{Artigo Original}

\section{Gestão em Saúde}

São realizados cursos, os quais os próprios servidores da rede fazem a solicitação, vinculado a aquilo que acham importante ou possuem necessidade [...] (Macunaíma).

[...] a gente acaba entrando trabalhar, e tu aprende a trabalhar, então aprendi trabalhando [...] a gente não tem um curso para entrar no serviço (Dom Quixote).

Apesar de ser visível que, no âmbito das práticas educativas elucidadas nos dados, prevalecem processos centrados em cursos e capacitações, considera-se que, ainda assim, são considerados (ainda não problematizados) os processos do cotidiano laboral. É com base na interação com a realidade que se pode transformar e intervir, e é por meio do desenvolvimento da capacidade de "aprender fazendo" que essa interação se consolida. O fazer educativo implica na relação com a sua natureza, ou seja, necessita-se explorar as variadas extensões que norteiam o conteúdo da prática, tornando o sujeito conhecedor da realidade mais seguro na realização de suas atividades, satisfazendo-o ${ }^{11}$. A educação que Freire defende é a que possibilita ao indivíduo a capacidade de compreender, não somente para se habituar, mas principalmente para transformar a realidade, intervindo e recriando-a. Somente mediante a interpretação da realidade que os sujeitos se tornam instruídos a modificála, ação da qual é considerada complexa se comparada ao simplesmente adaptar-se a ela ${ }^{25}$.

Neste sentido, as demandas de EPS, referidas pelos coordenadores dos CS, ocorrem mediante as dificuldades encontradas no dia-a-dia do processo de trabalho, percebidas tanto pelos profissionais como pela equipe ou até mesmo pela população, como pontuado nas falas a seguir:

[...] na equipe a gente sempre trabalha esses assuntos [EPS] conforme as dificuldades (A Moreninha).

[...] todos os anos a gente faz planejamento das atividades anuais, e eles também sugerem vários pontos que tem que estar melhorando, e também de acordo com a demanda que acontece no dia a dia (Macunaíma). 
Embora os discursos apontem para processos de educação organizados a partir das demandas do trabalhador, ou seja, das necessidades cotidianas, é possível observar, mais uma vez, que a estrutura das ações ocorre mediante capacitações, de forma verticalizada, ou seja, os profissionais são chamados em dias "marcados". Para Freire, os processos educativos não devem ser realizados a partir dos pressupostos da educação bancária, a qual impossibilita os educadores, como se eles estivessem sob efeito anestésico, inibindo os educandos do poder de criação ${ }^{11}$. A prática deve seguir os pressupostos da educação problematizadora, de consciência reflexiva, resultante em permanentes ações de transformar a realidade. A prática bancária propõe manter o depósito de conteúdos, já a problematizadora, ao contrário, busca as transformações das consciências, que culmina na reflexão crítica na realidade.

Embora hajam iniciativas educativas ancoradas na demanda local, elas não advém de reflexões conjuntas, a partir de "rodas de conversa" sobre o cotidiano da equipe e partindo da problematização deste cotidiano. Sobre isso, Paulo Freire refere que o educar não pode ser eficaz se não for relacionado ao contexto democrático das ligações estabelecidas entre educandos e educadores, e entre os próprios educandos. A educação realizada "em círculos" possibilita ao grupo que sejam realizadas reflexões e discussões sobre as problemáticas e necessidades encontradas no dia-adia. Desse modo, as rodas de conversa baseiam-se em um meio indispensável e essencial de conscientização capaz de transformar de forma radicalizada as ações laborais frente à vida. Considera-se que a EPS não se caracteriza por apresentar algo novo, mas sim fazer relembrar o que está guardado na memória, reavaliar e modificar as ações a partir dessa análise ${ }^{24}$.

Como discutido anteriormente, para o Ministério da Saúde a EPS ocorre no cotidiano das organizações e do trabalho, tendo como motivação os problemas enfrentados na realidade e levando em consideração conhecimentos e experiências das pessoas. A EPS oferece elementos significativos ao prover uma visão geral para o processo de formação profissional e aperfeiçoamento constante dos trabalhadores quanto aos desafios do processo de trabalho ${ }^{14}$.

Uma problemática para realizar ações de EPS encontrada nos discursos foi a falta de interesse profissional (S2) para aprender, que se distingue também quando os profissionais realizam práticas de educação voltadas à comunidade. Parece mais 
Artigo Original

Gestão em Saúde

cômodo permanecer entre os muros do serviço, embora os maiores problemas sociais estejam no âmbito do território. Para os entrevistados isso ocorre devido à falta de motivação e/ou de perfil dos profissionais para atuar neste modelo de atenção à saúde, sobretudo da categoria médica.

[...] as vezes tu fica numa saia justa porque se dispõe a fazer esse trabalho, vai até a escola, fala com o professor e a diretora [da escola da comunidade] [...] só que as vezes alguém da equipe, por vários motivos: "olha eu não posso eu não vou ou eu não quero", aí você fica sozinho para fazer (O Primo Basílio).

A questão de ESF precisa ser muito focada, ainda, porque têm muitos profissionais que sabem que é importante, que gostam e que fazem, mas têm outros que não conseguem entender o que é Saúde da Família, não sei se é por perfil ou porque não querem (Condessa Vésper).

Eu acho que precisa enfatizar bastante esta parte de ESF, porque realmente é uma estratégia viável [...] mas há profissionais que não se enquadram nisso, que ainda vêm com aquela mentalidade de que o médico é o responsável pela saúde da população, não conseguem entender que todos os outros profissionais também contribuem para isso e que ele [médico] precisa também sair do consultório, precisa conversar com a enfermeira, fisioterapeuta, auxiliar de enfermagem, para melhorar a assistência (Condessa Vésper).

Apesar de iniciativas de reorientação do modelo de atenção, como a ESF, os processos de formação não atendem a exigência desse novo modelo, estando ainda, na maioria das escolas de formação superior, direcionados ao modelo biologicista e "médicocentrado". Por isso, em 2004, a PNEPS emerge no sentido de qualificar o profissional da ESF. Paralelo a isso, ocorre a adoção de metodologias mais ativas de ensino-aprendizagem, previstas nas Diretrizes Curriculares Nacionais (DCN), voltadas ao desenvolvimento do SUS e à perspectiva da multiprofissional e transdisciplinaridade 9 . Mesmo com tais iniciativas, o que prevalece, no âmbito do serviço e do ensino em saúde, é a hegemonia do modelo biomédico. 
A Educação para a comunidade (S3) como necessidade advinda do aprender emerge como desafio, presente entre os entraves para a consolidação do modelo da ESF. Nesse sentido, caberiam ações de EPS voltadas também à população, e estas são percebidas pelas lideranças da ABS. Segundo os discursos, as ações de EPS realizadas no âmbito do CS estão voltadas à comunidade, em forma de grupos e com o objetivo de prevenir doenças (ainda não na lógica de promover saúde) e as ações vindas da Secretaria Municipal de Saúde, direcionadas, sobretudo, aos profissionais.

Aqui na unidade a gente acaba voltando as nossas ações para o público, os pacientes [...] a gente acaba voltando educação permanente para a população, tudo para a população: é grupo de educação permanente para a prevenção da população [...] (Dom Quixote).

A gente está planejando as ações na escola, higiene, saúde bucal, porque falta o enfermeiro ir na escola, médico ir na escola, conferir calendário das crianças. [...] aqui no bairro temos muitas casas com problemas de bebidas alcoólicas, então isso a gente precisa estar pensando em alguma atividade de educação permanente (Memórias Póstumas de Brás Cubas).

Nesse ponto nota-se a menção à Educação Popular como possibilidade no âmbito da EPS. O movimento de Educação Popular foi uma das variadas maneiras de mobilização educacional de massas adotadas no Brasil ${ }^{10}$. Um dos ideários da Educação Popular foi a formação de uma nova epistemologia fundamentada no respeito pelo senso comum que norteiam os elementos populares em sua prática cotidiana, problematizando-o, buscando descobrir a demanda presente na teoria popular, teoria esta ainda não descoberta pelo povo, possibilitando um raciocínio mais rigoroso, científico e unitário ${ }^{26}$.

Para muitos educadores, a Educação Permanente em Saúde configura um desdobramento da Educação Popular ou da Educação de Jovens e Adultos, perfilando-se pelos princípios e/ou diretrizes desencadeados por Paulo Freire desde Educação e Conscientização/Educação como Prática da Liberdade/Educação e Mudança, passando pela Pedagogia do Oprimido, Pedagogia da Esperança, Pedagogia da Cidade, Pedagogia da Autonomia e 
Pedagogia da Indignação. De Paulo Freire provém a noção de aprendizagem significativa, por exemplo26:162.

A formação em saúde, quando adotada a partir da lógica da EPS, não pode ser destinada somente para busca de diagnóstico, tratamento, prognóstico, etiologia e profilaxia das patologias. Ela deve instigar o profissional a buscar formas de realizar ações que favoreçam a atenção às necessidades de saúde dos usuários do serviço, bem como ser capaz de resolver enfrentamentos de gestão setorial e do controle social em saúde, como facilitadora do desenvolvimento de profissionais com autonomia e poder de formulação das práticas do cuidado ${ }^{9}$. Assim, os pressupostos freireanos que permeiam a PNEPS consideram a participação e o diálogo como elementos fundamentais à autonomia dos sujeitos ${ }^{10,11,24}$. $O$ ato de observar a realidade, a fim de transformar ações, problematizando o processo de trabalho e construindo significados e práticas só é possível mediante participação ativa de todos os envolvidos no processo, de onde os coordenadores dos CS, como gestores do cuidado, são elementos fundamentais, como apoiadores e atores do processo. Para tanto, é imprescindível que esse coletivo compreenda os princípios da EPS como uma idéia força e uma importante estratégia de gestão para mudanças dos processos de trabalho ${ }^{15,16}$.

\section{CONCLUSÃO}

As percepções dos coordenadores dos CS sobre os processos de EPS tangenciam os pressupostos políticos que operam à luz da obra textual do educador Paulo Freire.

Ao pensar a EPS como qualificação profissional (C1), os sujeitos levam em conta um processo de atualização constante, vivenciado no cotidiano, como norteador da prática laboral, porém, com intuito de resolver problemas pontuais, sem considerar a práxis.

As ações estão interligadas ao processo de trabalho da equipe multiprofissional, sobretudo com a participação do NASF, mais recentemente. Alguns coordenadores chamam atenção para o apoio incipiente da Secretaria Municipal de Saúde, que proporciona capacitações esporádicas aos servidores, bem como as ações voltadas a grupos específicos, beneficiando somente algumas categorias 


\section{Artigo Original}

\section{Gestão em Saúde}

profissionais, distanciando-se da lógica interdisciplinar. Nessa direção, os coordenadores guardam a noção de Educação Permanente como Educação Continuada, compreendida mediante a aplicação do conhecimento teórico especializado, pontual, e desconsiderando os nós provenientes do processo laboral.

$\mathrm{Na}$ segunda categoria (C2), percebe-se a falta de interesse profissional para realização de reflexões do cotidiano, pela prevalência de profissionais sem perfil e desconhecedores da essência do trabalho das equipes de Saúde da Família (hegemonia do modelo biomédico). Os processos educativos também ocorrem a partir das relações com a comunidade, através de grupos, possibilitando aos profissionais aprenderem com os usuários e não somente ensiná-los, o que se aproxima dos pressupostos de Paulo Freire, quando teoriza 0 aprender dos sujeitos em comunidade, mediatizados pelo mundo.

O presente estudo proporciona subsídios sobre como gestores da ABS necessitam apropriar-se de conceitos direcionadores dos processos de consolidação do SUS, como é o caso da EPS, os quais são fundamentais para o fortalecimento da gestão e para a execução de suas atividades no município, aumentando assim a qualidade deste nível de atenção. Outrossim, para que a EPS se consolide como estratégia política, operadora das mudanças na prática de $A B S$, será preciso maior compreensão e envolvimento dos coordenadores sobre esse processo como uma importante ferramenta de gestão.

\section{REFERÊNCIAS}

1. Ferraz F, Backes VMS, Mercado-Martínez FJ, Prado ML do. Políticas e programas de educação permanente em saúde no Brasil: revisão integrativa da literatura. Sau. Transf. Soc. 2012; 3(2):113-28.

2. Ceccim RB, Bravin FP, Santos AA. Educação na saúde, saúde coletiva e ciências políticas: uma analise da formação e desenvolvimento para o Sistema Único de Saúde como política pública. Lugar Comum (UFRJ). 2009; 28:159-180.

3. Ministério da Saúde. Secretaria de Atenção à Saúde. Departamento de Atenção Básica. Política Nacional de Atenção Básica. Brasília, 2012. 110 p.

4. Rosa WAG, Labate RC. Programa Saúde da Família: a construção de um novo modelo de assistência. Rev Latino-am Enfermagem. 2005;13(6):1027-34. 
5. Backes DS, Backes MS, Erdmann AL, Büscher A. O papel profissional do enfermeiro no Sistema Único de Saúde: da saúde comunitária à estratégia de saúde da família. Ciênc. saúde coletiva. Disponível em: $<$ http://www.scielo.br/scielo.php?script=sci_arttext\&pid=S141381232012000100024>. Acesso em: julho de 2015.

6. Ministério da Saúde. Secretaria de Assistência à Saúde. Coordenação de Saúde da Comunidade. Saúde da Família: uma estratégia para a reorientação do modelo assistencial.Brasília. Ministério da Saúde, 1997.

7. Congresso Nacional. Constituição da República Federativa do Brasil. Promulgada em 05 de outubro de 1988. [documento internet] 1988. Disponível em: < http://www.planalto.gov.br/legislacao/>. Acesso em: 12 nov. 2012.

8. Da Ros MA. Políticas Públicas de Saúde no Brasil. In: Palma MBA, Estevão A, Da Ros MA. (org.) A saúde em debate na educação física. Blumenau: Nova Letra; 2006. p. 240.

9. Ministério da Saúde. Portaria GM/MS no 198/04, de 13 de fevereiro de 2004: institui a Política Nacional de Educação Permanente em Saúde como estratégia do Sistema Único de Saúde para a formação e o desenvolvimento de trabalhadores para o setor e dá outras providências. Brasilia: Ministério da Saúde, 2004.

10 Freire P. Educação e mudança. 24. ed. São Paulo: Paz e Terra; 2001.p 148.

11. Freire P. Pedagogia do oprimido. 41 ed. Rio de Janeiro: Paz e Terra; 2005.p. 213.

12. Freire $P$. Pedagogia da autonomia: saberes necessários à prática educativa.43 ed. São Paulo: Paz e Terra; 2009. p148.

13. Faria RMB. Institucionalização da política de Educação Permanente para o SUS: Brasil, 1997-2006. [Tese]. [São Paulo]: Faculdade de Medicina da Universidade de São Paulo; 2008. 236p.

14. Ministério da Saúde. Portaria GM/MS no 1.996/07, de 20 de agosto de 2007: dispõe sobre as diretrizes para a implementação da Política Nacional de Educação Permanente em Saúde. Brasília: Ministério da Saúde, 2007.

15. Ferraz F, Vendruscolo C, Kleba EM, Prado ML, Reibnitz KS. Ações estruturantes interministeriais para reorientação da Atenção Básica em Saúde: convergência entre educação e humanização. Rev. O Mundo da Saúde. 2012; 36(3):482-93. 


\section{Artigo Original}

\section{Gestão em Saúde}

16. Vendruscolo C, Kleba ME, Krauzer IM, Hillsheim A. Planejamento situacional na Estratégia Saúde da Família: atividade de integração ensino-serviço na enfermagem. Rev Gaúcha Enferm. 2010; 31(1):183-86.

17. Ministério da Saúde. Norma Operacional da Assistência à Saúde - NOAS-SUS de 26 de janeiro de 2001. "Regionalização da Assistência à Saúde: aprofundando a descentralização com eqüidade no acesso". Série A. Normas e Manuais Técnicos. Brasília (DF): MS; 2001.

18. Bardin L. Análise de conteúdo. São Paulo: edições 70; 2011. 279 p.

19. Carvalho Y M, Ceccim RB. Formação e educação em saúde: aprendizados com a saúde coletiva. In: CAMPOS GWS. et al. (Orgs.) Tratado de Saúde Coletiva. São Paulo/Rio de Janeiro: Hucitec/Fiocruz; 2006. 968 p.

20. Motta JIJ, Ribeiro ECO. Educação permanente como estratégia na reorganização dos serviços de saúde. Março de 2005. Disponível em: www.redeunida.org.br. Acesso em: 13 out. 2013

21. Mancia JR; Cabral LC; Koerich MS. Educação Permanente no contexto da Enfermagem e da Saúde. 2004; 57(5):605-10.

22. Ministério da Saúde. Portaria oㅡ 2.527, de 19 de outubro de 2006. Define os conteúdos mínimos do Curso Introdutório para profissionais da Saúde da Família. Brasília: Ministério da Saúde; 2006.

23. Ministério da Saúde. Portaria ํo 154, de 24 de janeiro de 2008. Cria os Núcleos de Apoio à Saúde da Família (NASF). Disponível em: http://189.28.128.100/dab/docs/legislacao/portaria154_04_03_08_re.pdf. Acesso em: 03 de setembro de 2013.

24. Freire P. Conscientização: teoria e prática da libertação: uma introdução ao pensamento de Paulo Freire. São Paulo: Centauro; 2001. 116p.

25. Gadotti M. A voz do biógrafo brasileiro a prática à altura do sonho. In: Gadotti M. (Org.) Paulo Freire: uma biobibliografia. São Paulo: Cortez: Instituto Paulo Freire: UNESCO; 1996. p. 69-115.

26. Ceccim RB. Educação Permanente em Saúde: desafio ambicioso e necessário. Interface. 2005; 9(16):161-168. 
Artigo Original

Gestão em Saúde

27. Ceccim RB, Feuerwerker LMC. O quadrilátero da formação para a área da saúde: ensino, gestão, atenção e controle social. Physis. 2004;14(1):41-65. 